\title{
RESERVA EXTRATIVISTA LAGO DO CEDRO: BUSCA PELA SOBREVIVÊNCIA EM ARUANÃ (GO)
}

\author{
Bruno Augusto de Souza ${ }^{1}$
}

Resumo: Este artigo tem como foco o contexto de criação de uma Reserva Extrativista (Resex) em Goiás, a Resex Lago do Cedro, localizada no município de Aruanã (GO). O objetivo é: Compreender como a criação de uma Reserva Extrativista é benéfica para a proteção da sociobiodiversidade do Cerrado em sua localização específica. A discussão por nós realizada em torno dessa Unidade de Conservação gravita na questão de conservação da sociobiodiversidade, importante para os seres que a utilizam para sustento e sobrevivência. Aplicamos uma abordagem territorial do Cerrado como proposta analítica, tal abordagem é fundada em fatos concretos que atestam as contradições existentes no território do Cerrado. $\mathrm{Na}$ segunda metade do século XX, esse território foi enormemente alterado, muito em função da Revolução Verde, que drasticamente modificou as técnicas de plantio e colheita, degradando o Cerrado rapidamente e prejudicando as formas de sobrevivência para os seres humanos, animais e vegetais.

Palavras-chave: Cerrado; Sociobiodiversidade; Reserva Extrativista Lago do Cedro.

\section{EXTRACTIVE RESERVE LAGO DO CEDRO: SEARCH FOR SURVIVAL IN ARUANÃ (GO)}

\begin{abstract}
This article focuses on the context of the creation of an Extractive Reserve in Goiás, the Resex Lago do Cedro, located in the municipality of Aruanã (GO). The objective is: To understand how a creation of an Extractive Reserve is important to protection of the socio-biodiversity of the Cerrado. The discussion for us was held in a unit of gravitational conservation on the sustainability issue of socio-biodiversity, important for humans who are used to sustain and survive. Applying a territorial approach of the Cerrado as an analytical proposal, this approach is applied in the concrete facts that represent the contradictions existing in the territory of the Cerrado. In the second half of the twentieth century, the theme was greatly altered, much in execution in the Green Revolution, which changed drastically as techniques of planting and harvesting, degrading the Cerrado and damaging the survival forms for humans, animals and vegetables.
\end{abstract}

Keywords: Cerrado; Sociobiodiversity; Extractive Reserve; Lago do Cedro.

\footnotetext{
${ }^{1}$ Doutorando em Geografia pelo Instituto de Estudos Socioambientais (IESA) da Universidade Federal de Goiás (UFG), Brasil.b.a.desouza@hotmail.com.

Estudos Geográficos, Rio Claro, 17: 43-55, jan./jun. 2019 (ISSN 1678-698X) http://www.periodicos.rc.biblioteca.unesp.br/index.php/estgeo
} 


\section{INTRODUÇÃO}

O Cerrado brasileiro é uma área delimitada com características naturais específicas, com espécies vegetais e animais, assim como população humana residindo em áreas rurais e urbanas.

Esse território ao longo dos séculos, especialmente na segunda metade do século $X X$, conheceu drásticas alterações em seu meio natural, muito em função das práticas de plantio e colheita utilizadas no período em questão, conhecida como Revolução Verde.

Com as negativas alterações impressas na paisagem do Cerrado, algumas ações se efetivaram na busca de proteção do que restou desse território, importante para os seres humanos, assim como para os animais e vegetais residentes.

Neste artigo buscamos a análise de uma realidade específica, de uma Reserva Extrativista existente no estado de Goiás, a Reserva Extrativista Lago do Cedro, localizada no município de Aruanã.

Utilizamos a categoria território em função do que a Reserva Extrativista representa, assim como o contexto de sua criação. A utilização das categorias na Geografia servem, em nosso entendimento, na busca de análise e compreensão das realidades existentes no Planeta Terra.

O tema utilizado aborda o viés da sociobiodiversidade. Compreende-se que tal tema é de primordial importância para o ser humano que vive/reside em determinadas localidades, visto que o Planeta Terra é um sistema aberto e é afetado por práticas diversas, e temos o ser humano como agente que altera com maior rapidez e brutalidade esse sistema.

Este artigo faz parte do Projeto "Sociobiodiversidade e Desenvolvimento Territorial: perspectivas para o mundo do Cerrado", financiado pela CAPES-PGPSE.

\section{NATUREZA! O PALCO DE CONFLITOS SOCIOESPACIAIS}

A natureza pode ter inúmeros significados, dependerá do ponto de vista e também para que a mesma será utilizada. O conceito de natureza não é natural, nos apoiamos em Porto-Gonçalves (2006, p. 23) para explicar:

Toda sociedade, toda cultura cria, inventa, institui uma determinada idéia do que seja a natureza. Nesse sentido, o conceito de natureza não é natural, sendo na verdade criado e instituído pelos homens. Constitui um dos pilares através do qual os homens erguem as suas relações sociais, sua produção material e espiritual, enfim, a sua cultura.

Mais que afirmar que cada sociedade possui uma concepção de natureza, salientamos que os diferentes segmentos da sociedade possuem diversas concepções de natureza.

Pois bem, há aqueles que indicarão a natureza como meio de sobrevivência, isso é perfeitamente aceitável em certo aspecto... Até o ponto de que essa sobrevivência não signifique o total esgotamento do meio natural ao qual determinada (o) pessoa/família/grupo de interesse utiliza para a sobrevivência.

Estudos Geográficos, Rio Claro, 17: 43-55, jan./jun. 2019 (ISSN 1678-698X) http://www.periodicos.rc.biblioteca.unesp.br/index.php/estgeo 
Ao leitor deste artigo, redigido no século XXI, ano de 2019, significa que no Brasil se tornou primordial a exploração da natureza "natural" para o avanço econômico do país. O problema é que esse avanço não beneficia a população em geral, e sim grupos hegemônicos ${ }^{2}$ nacionais e internacionais.

Há um agravante! Determinados grupos de seres humanos não consideram o ser humano como natureza, fato que condiz com a avassaladora predação realizada em enormes territórios ao longo do Planeta Terra.

A exploração da natureza que remetemos é a extração predatória de recursos, como especialmente, a água. Focamos no Cerrado, localização específica no Brasil que se ressalta possuir uma relevante hidrografia, por conta de que é o berço de importantes bacias hidrográficas como: Araguaia/Tocantins, Platina e São Francisco (Mapa 01).

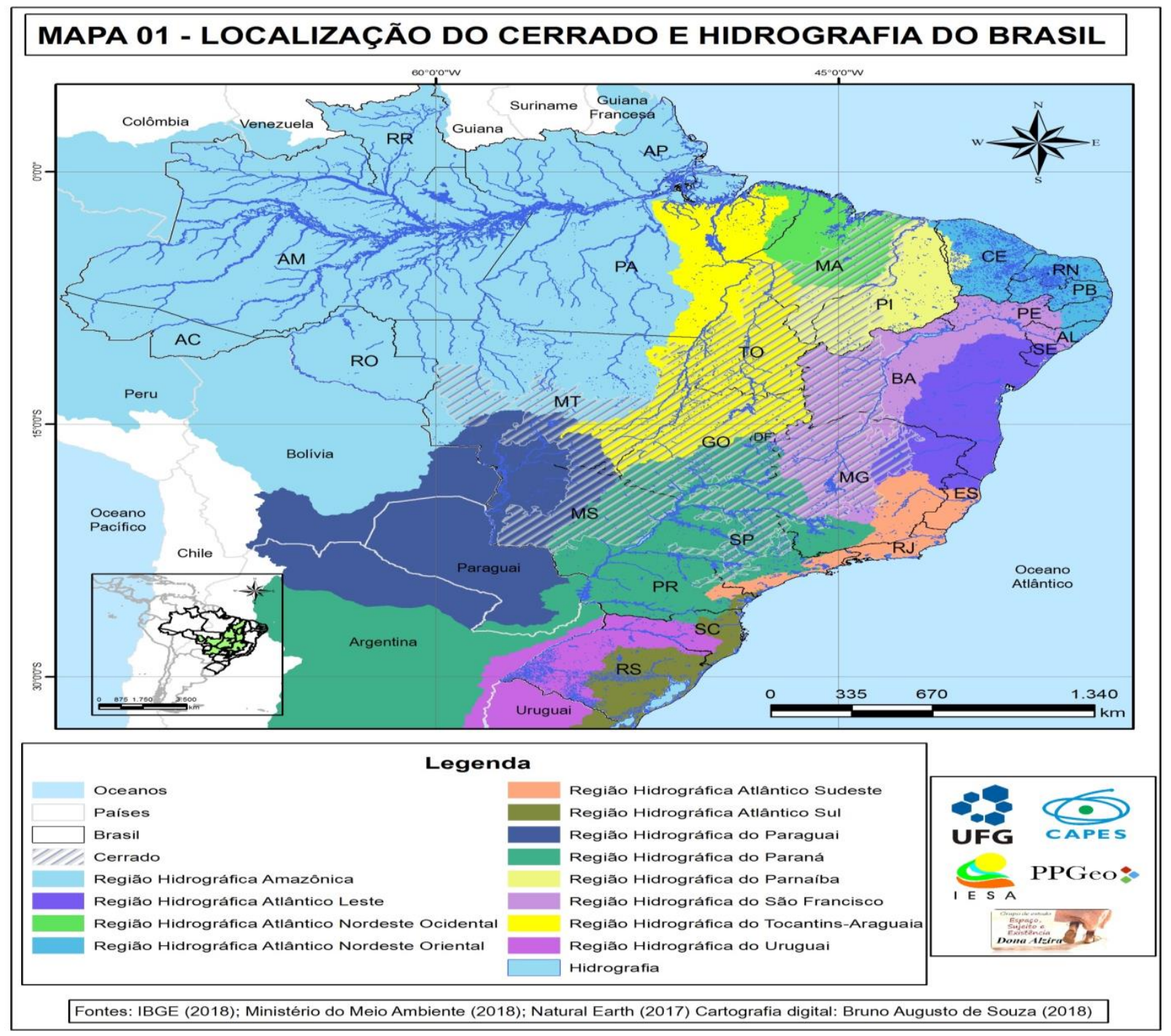

\footnotetext{
${ }^{2}$ Grupos hegemônicos são grupos que incidem sua supremacia sobre outros grupos. Infelizmente, no mundo, isso significa estabelecer suas formas de dominação a qualquer custo. No tocante dos ambientes naturais, ocorrem extrações dos recursos de maneira predatória e avassaladora, por parte dos grupos hegemônicos a que nos referimos. Fazem parte desses grupos: políticos, produtores agropecuários com grandes latifúndios, empresas mineradoras, empresas fabricantes de agrotóxicos, dentre outros.

Estudos Geográficos, Rio Claro, 17: 43-55, jan./jun. 2019 (ISSN 1678-698X) http://www.periodicos.rc.biblioteca.unesp.br/index.php/estgeo
} 
A respeito do ambiente natural do Cerrado, Castilho e Chaveiro (2010, p. 3839) afirmam:

Em extensão, o domínio do Cerrado é o segundo maior do Brasil. Sua área original era de dois (2) milhões de quilômetros quadrados. Abrange grande área da região Centro-Oeste brasileira como também partes do Norte, Nordeste e Sudeste. O clima é subtropical, semiúmido com duas estações definidas: uma úmida (verão chuvoso) e outra seca (inverno seco). O solo, em grande parte, é deficiente em nutrientes, porém rico em ferro e alumínio. Esses fatores, sobretudo o clima, influenciam um tipo de vegetação peculiar.

O Cerrado possui diversas espécies endêmicas ${ }^{3}$ e sofre uma perda brutal de habitat. Do ponto de vista da diversidade biológica, o Cerrado brasileiro é considerado a savana mais rica do mundo, com 11.627 espécies de plantas nativas já catalogadas. Entre os animais, cerca de 199 espécies de mamíferos, 837 espécies de aves, 1.200 espécies de peixes, 180 espécies de répteis, e 150 espécies de anfíbios são conhecidas. A porcentagem de anfíbios e répteis endêmicos é de: $28 \%$ e $17 \%$ respectivamente. De acordo com estimativas recentes, o Cerrado é refúgio de $13 \%$ das borboletas, $35 \%$ das abelhas e $23 \%$ dos cupins dos trópicos (MMA, 2018).

Tais números colocam o Cerrado como um dos territórios de maior riqueza em biodiversidade e um dos maiores em espécies endêmicas. Infelizmente, essa riqueza vem sendo destruída pela forma como a modernização avança em seu território (CASTILHO e CHAVEIRO, 2010).

Além da rica diversidade biológica, o Cerrado possui grande importância social. Muitas populações sobrevivem de seus recursos naturais, como: etnias indígenas, quilombolas, geraizeiros, ribeirinhos, babaçueiras, vazanteiros e quilombolas que, fazem parte do patrimônio histórico e cultural brasileiro, e detêm um conhecimento tradicional de sua biodiversidade (MMA, 2018).

No Cerrado, mais de 10 tipos de frutos comestíveis são regularmente consumidos pela população local e vendidos nos centros urbanos, como: Pequi, Buriti, Mangaba, Cagaita, Bacupari, Cajuzinho do Cerrado, Araticum e as sementes do Baru (MMA, 2018) (Imagem 01).

\footnotetext{
${ }^{3}$ Espécies endêmicas são espécies que ocorrem exclusivamente em uma determinada localidade.

Estudos Geográficos, Rio Claro, 17: 43-55, jan./jun. 2019 (ISSN 1678-698X) http://www.periodicos.rc.biblioteca.unesp.br/index.php/estgeo
} 


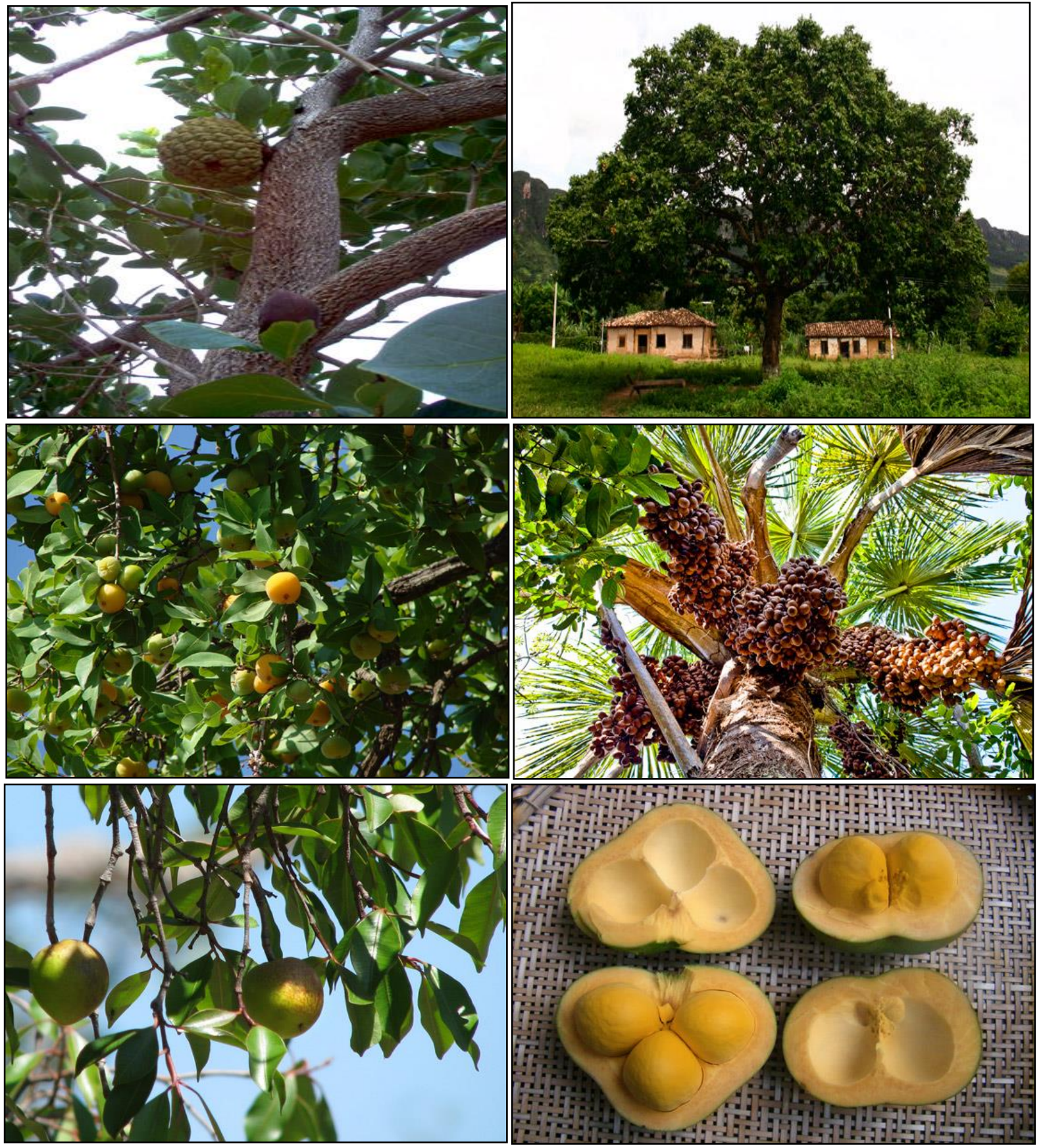

Imagem 01 - Mosaico de imagens com frutos comestíveis do Cerrado (Araticum, árvore de Baru, Cagaita, Buriti, Mangaba, Pequi)

Fonte: Cerratinga (2018).

Inúmeras espécies de plantas e animais correm risco de extinção no Cerrado. Estima-se que $20 \%$ das espécies nativas e endêmicas já não ocorram em áreas protegidas e que 137 espécies de animais estão ameaçadas de extinção. Depois da Mata Atlântica, o Cerrado é o ecossistema brasileiro que mais sofreu alterações com a ocupação humana. Com a crescente pressão para a abertura de novas áreas para produção de carne e grãos para exportação, ocorre um progressivo esgotamento de seus recursos naturais. Além disso, o Cerrado é palco Estudos Geográficos, Rio Claro, 17: 43-55, jan./jun. 2019 (ISSN 1678-698X) http://www.periodicos.rc.biblioteca.unesp.br/index.php/estgeo 
de uma exploração extremamente predatória de seu material lenhoso para produção de carvão (MMA, 2018).

Em muitos discursos para o "desenvolvimento" da sociedade, há a afirmação na necessidade de dominação da natureza, mas se considerarmos o ser humano como parte da natureza, isso significa que há a necessidade de dominação do ser humano pelo próprio ser humano. Porto-Gonçalves (2006, p. 26) afirma:

[...] a expressão dominar a natureza só tem sentido a partir da premissa de que o homem é não-natureza... Mas se o homem é também natureza, como falar em dominar a natureza? Teríamos que falar em dominar o homem também... E aqui a contradição fica evidente. Afinal, quem dominaria o homem? Outro homem? Isso só seria concebível se aceitássemos a idéia de um homem superior, de uma raça superior, pura - e a História já demonstrou à farta as consequências destas concepções.

Partimos do pressuposto que o ser humano também é natureza, pois, em seu processo evolutivo, o mesmo se agregou ao ambiente natural. Devemos citar que existem inúmeros discursos que tratam outros seres humanos como inferiores, considerando gênero, religião ou etnia, entre diversos fatores. O ponto central destes discursos é a dominação por pequena casta da sociedade em busca de privilégios.

Para compreender o contexto de desvinculação da natureza como algo "humano", assim consequentemente, tornando-a objeto de utilização da raça humana, Porto-Gonçalves (2006, p. 34) afirma que:

[...] O antropocentrismo e o sentido pragmático-utilitarista do pensamento cartesiano não podem ser vistos desvinculados do mercantilismo que se afirmava e já se tornava, com o colonialismo, senhor e possuidor de todo o mundo. Afinal, na Idade Média, a riqueza dos senhores feudais e da Igreja advinha da propriedade da terra e [...] da exploração dos servos [...]. Com o desenvolvimento mercantil e, com ele, da burguesia a riqueza passa cada vez mais a depender da técnica [...]. O antropocentrismo consagrará a capacidade humana de dominar a natureza. Esta, dessacralizada já que não mais povoada por deuses, pode ser tornada objeto e, já que não tem alma, pode ser dividida, tal como o corpo já o tinha sido na Idade Média.

Casseti (1994, p. 103-104, grifo do autor) ressalta que:

[...] o conceito de natureza passa por uma mutação radical, correlativa às grandes mudanças que ocorreram na própria evolução do conhecimento. Nesse momento, com a sistematização do conhecimento científico, a natureza assume uma característica própria de 'externalização', fundamentada na afirmação do poder humano sobre a natureza.

A explicação de não consideração do ser humano como natureza se assenta na sociedade capitalista, pois, a ideia de uma natureza exterior ao homem cristalizaEstudos Geográficos, Rio Claro, 17: 43-55, jan./jun. 2019 (ISSN 1678-698X) http://www.periodicos.rc.biblioteca.unesp.br/index.php/estgeo 
se com a civilização industrial inaugurada pelo capitalismo (PORTO-GONÇAVES, 2006).

Meio natural é tudo aquilo que evoluiu ao longo de séculos/milênios e perdura até os dias atuais na biosfera, como: solo, água, ar, plantas e animais. Não faremos uma discussão da evolução genética e sua capacidade de criação/manipulação de plantas e animais em geral, nossa discussão está centrada em algo geográfico, a relação social, espacial e econômica do ser humano com determinada localidade, e tal localidade se configura em um espaço natural.

Com a afirmação dos parágrafos anteriores, percebemos que não exaurir o ambiente natural é primordial para a existência do ser humano, pois sem ele, não há ser humano. A centralidade do pensamento deste artigo é de que sem o pleno funcionamento do ambiente natural, não haverá vida para o ser humano. Analisamos uma Reserva Extrativista que dispõe de recursos naturais para a existência dos seres que vivem em sua área.

O lluminismo, no século XVIII, se encarregou de "limpar" a filosofia renascentista de seus traços religiosos medievalistas. A crítica da metafísica - aquilo que está além da natureza - foi feita em nome da física, ou seja, em nome da natureza em seu sentido concreto, tangível, palpável. Essa concepção advém de que para compreender o mundo é necessário partir do próprio mundo e não de dogmas religiosos (PORTO-GONÇALVES, 2006).

Há de se pensar que a natureza "natural" é praticamente infinita no Planeta Terra, visto que os solos e oceanos formam uma imensidão, mas o problema é que não basta existir natureza para o usufruto do ser humano. Essa afirmação se pauta de que o ser humano pode utilizar pequena parcela da natureza para sua sobrevivência, e esse é o maior problema.

Além disso, atualmente, com a existência das propriedades privadas, a natureza é um fator comercial que nem todos, ou na realidade, poucos dispõe de meios para conseguir pequena parcela para seu usufruto. Praticamente tudo está "cercado", o que para nós, é algo surreal e bizarro. Do ponto de vista do conhecimento da superfície terrestre, com o advento do sensoriamento remoto no século XX, praticamente "tudo" pode ser visualizado.

Nem todo solo pode ser utilizado para plantações, nem toda água é passível de ser consumida, além de que com o passar dos séculos, se descobriu os melhores solos para plantações de determinadas culturas, além da ocorrência de canalizações para a utilização da água.

A partir do momento que se utiliza mais água doce, por exemplo, do que a capacidade de reposição, isso acarreta graves problemas para a população que reside na área afetada.

Citamos a questão da água, pois tal recurso está de forma gradual se esvaindo de localidades que estabelecem um regime de uso maior do que de reposição, alterando drasticamente a plena vivência dos seres em geral.

A Geografia possui uma enormidade de objetos que se pode "fazer" ciência. Alguns autores definem a Geografia como o estudo da superfície terrestre, outros definem como o estudo da paisagem (MORAES, 2005). Tal ciência elenca elementos diversos como objetos de estudo, e utilizam-se, por exemplo, metodologias variadas para tais objetivos.

A ciência geográfica busca, de alguma maneira, compreender os problemas perpassados em diferentes perspectivas. O positivo é de que se aliam inúmeros Estudos Geográficos, Rio Claro, 17: 43-55, jan.jun. 2019 (ISSN 1678-698X) http://www.periodicos.rc.biblioteca.unesp.br/index.php/estgeo 
elementos, como as questões sociais e ambientais. $E$ mais, não somente compreender, mas também buscar formas de melhorias para àqueles que sofrem as consequências de determinados problemas.

Partimos de que o foco do artigo é uma área específica criada por meio de um Decreto, por conta da pressão de um grupo particular. Então, a configuração de um território se estabelecerá de acordo com interesses mais ou menos perceptíveis em determinado espaço, pois mesmo que se exerça o poder a longas distâncias por meio das modernas tecnologias de informação, os alvos sempre estarão alocados a um espaço (SOUZA, 2013).

De acordo com Gomes (2008, p. 37), o território possui "[...] uma extensão física concreta, uma porção de área, bem delimitada, dispondo de objetos precisamente espacializados".

Na perspectiva de formação do território, nos apoiamos em Raffestin (1993, p. 143, grifo do autor), que afirma:

[...] O território se forma a partir do espaço, é o resultado de uma ação conduzida por um ator sintagmático (ator que realiza um programa) em qualquer nível. Ao se apropriar de um espaço, concreta ou abstratamente (por exemplo, pela representação), o ator "territorializa" o espaço.

Os territórios nada mais são que espaços criados e regidos por certas pessoas ou grupos. O território da Reserva Extrativista que analisamos faz parte de uma área rural do município de Aruanã, no estado de Goiás.

No que se refere à necessidade de territorializar um espaço e manter o controle sobre ele, Souza (2013, p. 88, grifos do autor) reitera que as motivações:

[...] sempre estarão, de algum modo, conectadas ao substrato espacial material e, eventualmente, também aos próprios significados culturais atribuídos às formas espaciais, isto é, às imagens do lugar. O desejo ou a cobiça com relação a um espaço podem ter relação com os recursos naturais da área em questão; podem ter a ver com o que se produz ou quem produz no espaço considerado; podem ter ligação com o valor estratégico-militar daquele espaço específico; e podem se vincular, também, às ligações afetivas e de identidade entre um grupo social e seu espaço.

Com as considerações até o momento, destacamos que os territórios só existem a partir de interesses diversos. Se não possuírem áreas de interesse, as localidades não se tornarão territórios. Como exemplo, os recursos naturais estão entre interesses primordiais para sobrevivência e exploração econômica.

O território se apoia no espaço, ele é uma produção a partir do espaço, se inscrevendo num campo de poder. Produzir uma representação do espaço já é uma apropriação, um controle por assim dizer. Qualquer projeto no espaço que é expresso por uma representação revela a imagem desejada de um território, de um local de relações (RAFFESTIN, 1993).

A criação de Reservas Extrativistas no Brasil é uma produção de território regida pelo Estado, visto que a partir de demandas específicas há a ação para a

Estudos Geográficos, Rio Claro, 17: 43-55, jan./jun. $2019 \quad$ (ISSN 1678 -698X) http://www.periodicos.rc.biblioteca.unesp.br/index.php/estgeo 
concepção dos decretos que regulam tais territórios. De acordo com Raffestin (1993, p. 152, grifos do autor):

As "imagens" territoriais revelam as relações de produção e consequentemente as relações de poder, e é decifrando-as que se chega à estrutura profunda. Do Estado ao indivíduo, passando por todas as organizações pequenas ou grandes, encontram-se atores sintagmáticos que "produzem" o território. De fato, o Estado está sempre organizando o território nacional por intermédio de novos recortes, de novas implantações e de novas ligações.

No contexto de organização do espaço, Almeida (2005, p. 108) afirma que:

[...] pode-se dizer que o território responde, em sua primeira instância, a necessidades econômicas, sociais e políticas de cada sociedade e, por isso, sua produção está sustentada pelas relações sociais que o atravessam. Sua função, porém, não se reduz a essa dimensão instrumental; ele é também objeto de operações simbólicas e é nele que os atores projetam suas concepções de mundo.

Raffestin (1993) relaciona a territorialidade como a reflexão da multidimensionalidade do vivido territorial, envolvendo o processo territorial e 0 produto territorial, e isso implica em relações existenciais e/ou produtivistas, pois ambas são relações de poder.

\section{CRIAÇÃO! A RESERVA EXTRATIVISTA LAGO DO CEDRO EM ARUANÃ (GO)}

O Decreto s/n de 11 de setembro de 2006 regulamenta a criação da Reserva Extrativista Lago do Cedro no município de Aruanã (GO) (Mapa 02), com o objetivo de proteger os meios de vida e a cultura da população extrativista residente na área de sua abrangência e assegurar o uso sustentável dos recursos naturais da unidade (BRASIL, 2017b).

Estudos Geográficos, Rio Claro, 17: 43-55, jan./jun. 2019 (ISSN 1678-698X) http://www.periodicos.rc.biblioteca.unesp.br/index.php/estgeo 


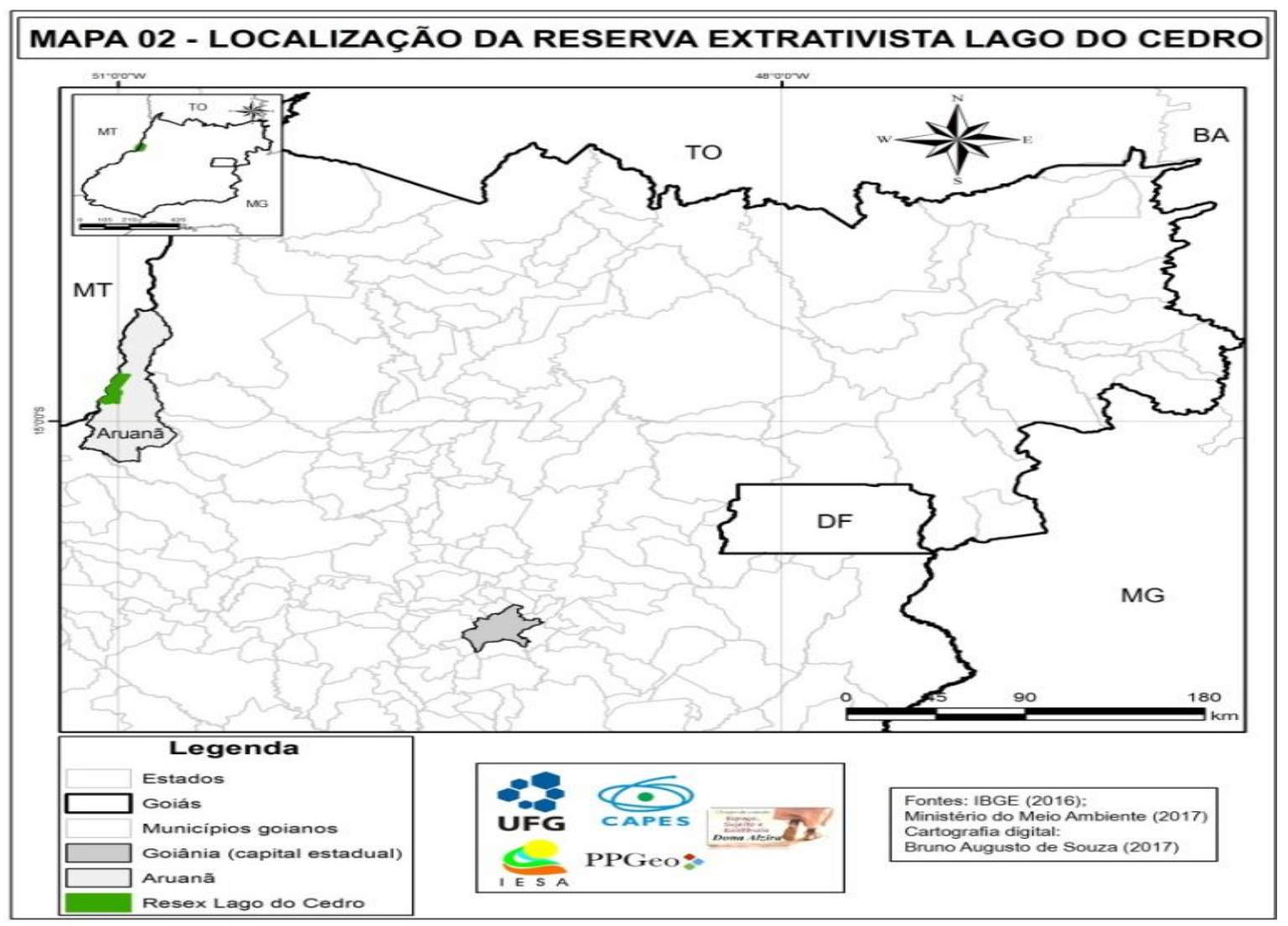

A população extrativista da Resex Lago do Cedro totaliza cerca de 120 beneficiários que não residem dentro das terras da Unidade de Conservação, mas sim em suas proximidades, e o extrativismo é baseado na pesca e na condução de visitantes para a pesca esportiva.

A criação das Resex no Brasil se encontra além da busca racional de elementos naturais, isso faz com que a extração nessa amplitude esteja no uso sustentável de uma determinada localidade e também na questão social dos moradores. De acordo com Rueda (1995, p. 11):

No caso concreto do Brasil, onde a defesa dos recursos naturais extrativos surgiu da luta dos extrativistas pela terra, o objetivo a conquistar não foi apenas um desenvolvimento sustentável, mas, "SOCIALMENTE JUSTO". A Reserva Extrativista deve conservar esta característica de concretização da justiça, mediante a atribuição da terra a aqueles que secularmente ali habitam e a defendem.

A evolução conceitual do extrativismo no Brasil, mediante a participação direta dos extrativistas, chegou a este avanço importante, consolidando a Reserva Extrativista não apenas como uma conquista ecológica, mas especialmente como uma conquista social.

A criação das Reservas Extrativistas no Brasil abarca principalmente formas sustentáveis de extrativismo com importância socioeconômica, contra o desflorestamento, e também como assentamento rural para as famílias que ali vivem

Estudos Geográficos, Rio Claro, 17: 43-55, jan./jun. 2019 (ISSN 1678-698X) http://www.periodicos.rc.biblioteca.unesp.br/index.php/estgeo 
para garantir sua permanência em detrimento de, por exemplo, agentes agropecuários ou ligados à mineração.

Na Reserva Extrativista Lago do Cedro ainda não foi feita a regularização fundiária para os beneficiários, é uma demanda em trâmite que perpassa por burocracias regulatórias. Mesmo sem a regularização fundiária, a existência da área preservada da Resex é benéfica para àqueles que a utilizam como meio de sustento e sobrevivência, assim como para as populações vegetais e da fauna que ali residem.

As Reservas Extrativistas possuem especificidades para que a família se torne uma beneficiária da área. A Portaria no 07 de 20 de janeiro de 2015 do Instituto Chico Mendes de Conservação da Biodiversidade (INSTITUTO CHICO MENDES, 2018) dispõe a respeito do perfil para que a família seja beneficiária da área da Resex Lago do Cedro, que é:

1. Para fins de definição do Perfil da Família Beneficiária da Reserva Extrativista Lago do Cedro são consideradas famílias beneficiárias aquelas que:

I - Atendam a no mínimo um dos seguintes critérios:

a) Tenham ancestralidade reconhecida pelos seus familiares;

b) Tenham o modo cultural dos pescadores;

c) Utilizem habitualmente os recursos pesqueiros do Rio Araguaia;

d) Dependam do uso dos lagos e recursos provindos da UC.

II - No mínimo um de seus membros se enquadre em pelo menos uma entre as seguintes categorias:

a) Ser pescador;

b) Ser vazanteiro;

c) Ser guia turístico do rio;

d) Ser guia de pesca;

e) Ser extrativista;

f) Viver mais de 15 (quinze) anos no município de Aruanã.

2. Os requisitos estabelecidos nos itens I e II do item 1. deverão ser atendidos cumulativamente.

Podemos citar as seguintes associações com representantes na Resex Lago do Cedro: Associação dos Barqueiros do Encontro dos Rios de Aruanã (ABGERA), Associação de Barqueiros de Aruanã (ABA), Associação de Ribeirinhos e Canoeiros de Aruanã (ARCA), Associação de Pescadores e Guias de Aruanã (ASPEGA), Colônia de Pescadores Z-7, e Povo Karajá de Aruanã/Aldeia Buridina.

\section{CONCLUSÕES}

A criação de Reservas Extrativistas é uma ação de proteção aos ambientes naturais, assim como das populações que dependem desses ambientes para sobrevivência. Mesmo que as áreas protegidas sejam minúsculas se comparadas com as áreas utilizadas pela agropecuária e mineração, a presença das Resex é benéfica para as populações que usufruem de suas riquezas.

O Cerrado, na segunda metade do século XX, sofreu drásticas alterações em razão do avanço da fronteira agrícola, dizimando os ambientes naturais que perduravam em seu território.

Estudos Geográficos, Rio Claro, 17: 43-55, jan./jun. 2019 (ISSN 1678-698X) http://www.periodicos.rc.biblioteca.unesp.br/index.php/estgeo 
A Resex Lago do Cedro é uma das duas Reservas Extrativistas do estado de Goiás ${ }^{4}$, se torna referência no aspecto de conservação ambiental, e esperamos que em um futuro próximo se torne referência também na questão fundiária para os beneficiários cadastrados na área.

\section{REFERÊNCIAS}

ALMEIDA, Maria Geralda de. Fronteiras, territórios e territorialidades. Revista da ANPEGE, n. 2, v. 1, p. 103-114, 2005.

BRASIL. Decreto s/n, de 11 de setembro de 2006. Dispõe sobre a criação da Reserva Extrativista Lago do Cedro, localizada no município de Aruanã, estado de Goiás, e dá outras providências. Disponível em <http://www.planalto.gov.br/ccivil_03/_Ato2004-2006/2006/Dnn/Dnn10968.htm>. Acesso em nov./2017b.

CASSETI, Valter. O relevo no contexto ideológico da natureza: uma nota. Boletim Goiano de Geografia, 14, p. 103-115, jan./dez. 1994.

CASTILHO, Denis; CHAVEIRO, Eguimar Felício. Por uma análise territorial do Cerrado. In: PELÁ, Márcia; CASTILHO, Denis (orgs.). Cerrados: perspectivas e olhares. Goiânia: Editora Vieira, 2010, p. 35-50.

CERRATINGA. Imagens de frutos comestíveis do Cerrado. Disponível em $<$ http://www.cerratinga.org.br/>. Acesso em dez./2018.

GOMES, Paulo Cesar da Costa. Sobre territórios, escalas e responsabilidade. In: HEIDRICH, Álvaro Luiz; COSTA, Benhur Pinós da; PIRES, Cláudia Luísa Zeferino; UEDA, Vanda (orgs.). A emergência da multiterritorialidade: a ressignificação da relação do humano com o espaço. Porto Alegre: Editora da UFRGS, 2008, p. 37-45.

INSTITUTO CHICO MENDES. Portaria no 07 de 20 de janeiro de 2015. Aprova o Perfil da Família Beneficiária da Reserva Extrativista Lago do Cedro. Disponível em $<\mathrm{http}$ ://www.icmbio.gov.br/portal/images/stories/documentos/portaria_07_de_20_de_ janeiro_de_2015.pdf>. Acesso em ago./2018.

MINISTÉRIO DO MEIO AMBIENTE (MMA). O Bioma Cerrado. Disponível em <http://www.mma.gov.br/biomas/cerrado>. Acesso em dez./2018.

MORAES, Antonio Carlos Robert. Geografia: Pequena História Crítica. 20aㅡ ed. São Paulo: Annablume, 2005.

PORTO-GONÇALVES, Carlos Walter. Os (des)caminhos do meio ambiente. 14 ed. - São Paulo: Contexto, 2006.

\footnotetext{
${ }^{4}$ A outra Reserva Extrativista do estado de Goiás é a Reserva Extrativista Recanto das Araras de Terra Ronca, que possui área nos municípios de Guarani de Goiás e São Domingos, especificamente no nordeste de Goiás.

Estudos Geográficos, Rio Claro, 17: 43-55, jan./jun. 2019 (ISSN 1678-698X) http://www.periodicos.rc.biblioteca.unesp.br/index.php/estgeo
} 
RAFFESTIN, Claude. Por uma Geografia do poder. São Paulo: Ática, 1993.

RUEDA, Rafael Pinzón. Evolução histórica do Extrativismo. In: MURRIETA, Julio Luiz; RUEDA, Rafael Pinzón (orgs.). Reservas extrativistas. UICN, Gland, Suíça e Cambridge, Reino Unido, 1995, p. 3-12.

SOUZA, Marcelo José Lopes de. Território e (des)territorialização. In: SOUZA, Marcelo José Lopes de. Os conceitos fundamentais da pesquisa sócio-espacial. Rio de Janeiro: Bertrand Brasil, 2013, p. 77-110.

Estudos Geográficos, Rio Claro, 17: 43-55, jan./jun. 2019 (ISSN 1678-698X) http://www.periodicos.rc.biblioteca.unesp.br/index.php/estgeo 